\title{
Management of Innovation Process in Services: Micro and Small Enterprises of the Metropolitan Region of Campinas
}

\author{
Tarik Veloso Dal Molin \\ Merial Animal Health Ltda., Campinas, Brazil \\ Luiz de Freitas Ayres \\ Mackenzie Presbyterian University, Campinas, Brazil \\ Antônio Henriques de Araujo Junior \\ State University of Rio de Janeiro, RJ, Brazil
}

\begin{abstract}
This study aimed to explore how processes of innovation are perceived and managed in micro and small service-oriented companies in Campinas, i.e., verifying how people in these companies understand, identify, and manage innovation (what tools or methodologies). Innovation is not a new concept, but its perception as a process, detached from randomness, is. This understanding is what allows its management as a tool to improve results and competitiveness, and to the perpetuation of the company. The research had a qualitative approach that consisted in the content analysis of structured interviews held with 10 respondents of five different companies, using eight innovation-focused questions, adapted from the Brazilian National Quality Foundation (FNQ). After interviews, four categories were identified: innovation understanding, innovative ambience, innovation process management, and learning during the process - the first two regarding the subjective features of innovation and the latter two the objective features. Analysis outcome has shown that companies understand the concept and importance of innovation, but still do not see it as a process, which leads them to try isolated initiatives, usually executed by instinct only. Due to the fact that innovation is not considered as a process, most practices encourage generation of ideas, instead of goals, key performance indicators (KPIs), and learning — this latter one, only occurs informally and over time.
\end{abstract}

Keywords: innovation process management, innovation, objective \& subjective aspects of innovation

\section{Introduction}

This study focuses on the innovation process management of small service-sector companies, specifically in micro and small businesses in the metropolitan region of Campinas, Brazil. According to Tidd, Bessant, and Pavitt, (2008) innovation is not a new concept, since there have always been innovations in human history, but its management is Cassiolato and Lastres (1998) state that the understanding how this management takes place

Tarik Veloso Dal Molin, B.S. in Communications and Administration, HR professional at Merial Animal Health Ltda., Campinas, Brazil.

Luiz de Freitas Ayres, Professor, M.Sc., teachers and researchers, Mackenzie Presbyterian University, Campinas, Brazil.

Antônio Henriques de Araujo Junior, Professor, Ph.D, teachers and researchers, the State University of Rio de Janeiro, Resende, Brazil.

Correspondence concerning this article should be addressed to Tarik Veloso Dal Molin, RuaOlavoBilac, 190 apto. 11-Cambuí, CEP: 13024-110, Campinas/SP-Brazil. 
in a new global context where organizations are inserted (Cassiolato \& Lastres, 1998) is highly relevant to the perpetuation and prosperity of companies. Managing and investing in innovations can enable organizations to remain competitive and active in a market increasingly complex (Gorni, Dreher, \& Machado, 2009).

Complexity even increases when considering the services sector, as there are additional characteristics to be taken into account (Sundbo, 1997). One example would be the ease of imitation, for it is not possible to register a patent for a service innovation (Sundbo, 1997). For this sector, it is even more important to understand innovation as a continuous process that acts as a channel of inexhaustible potential ideas that once filtered continues to generate innovations to keep the company in a favorable competitive position (Sebrae, 2009).

The world has changed a lot in the last 50 years. The line between products and services is increasingly tenuous and the amounts of new enterprises, that mix both, grow every day (Cassiolato \& Lastres, 1998). Yet, companies still struggle with their own competitiveness in complex scenarios lacking appropriate information on the topic innovation management. That context emerges the following research question: how are the processes of innovation perceived and managed in micro and small service sector companies in Campinas?

Furthermore, the objective is to verify how managers and employees of small businesses in the service sector understand, identify, and manage the innovation process. It aims, in particular, to verify what tools or methodologies are used to support and manage the innovation process in their company. It also aims to understand how managers and employees perceive and manage the innovative ambience in this type of company. It is expected to obtain this information to complement the research problem through the study of micro and small businesses in the metropolitan region of Campinas.

This paper is divided into five main sections for better organization: Introduction, Literature Review, Research Methods, Result Analysis, Conclusions, and References.

\section{Literature Review}

The concept of idea consists in proposing something new, that do not exist yet. The construction of this idea into matter or something tangible makes it an invention, once it takes the idea out of the abstract field and turns it into the physical. Finally, the application of this invention, when converted into results for the company, can be defined as innovation (Tidd et al., 2008). Examples of results for the company could be number of sales or acceptance of consumers to the novelty (Afuah, 2003).

There are two types of innovation; the first may be classified as discontinuous innovation, radical rupture or a breakthrough moment. In this case, changes are designed to leverage the business results from one level to anotherhigher level (Tidd et al., 2008). The second type of innovation can be classified as continuous innovation, evolutionary, or continuous improvement, which is often associated with Japanese practice Kaizen, in which small improvements are made systematically and consistently on processes already established and for which the perception of improvement in the outcome is incremental (Tidd et al., 2008). Concepts presented above have been formulated with an initial focus on products. Although it is important for understanding innovation in a systemic perspective, considering the new global context in which the importance of the service sector raises, there are four possible types of innovation in services (Sundbo \& Gallouj, 1998):

(a) Service Innovations: creation of a new type of service, previously not provided by the market.

(b) Process Innovations: new ways to provide a service to the client, in production processes or customer service directly. 
(c) Organizational Innovations: new ways to manage the organizational routine. It is noteworthy that it counts as innovation only if it generates measurable changes in the results.

(d) Market Innovations: new markets yet undiscovered.

Service companies can work simultaneously with one or more types of innovation presented above as they are not exclusive.

The drive to innovation in companies can impact the results of the innovation process directly. There is a paradigm related to the marketing aspect of innovation, named by the author as the Paradigm of Strategic Innovation (Sundbo, 1997). The Paradigm of Strategic Innovation applies to the service sector, because it emphasizes the main determinant for innovation as the company's own strategy, i.e., innovation is not useful to a company if it does not help in achieving its vision and strategic goals (Sundbo, 1997).

\section{Innovation Process}

There is no single approach to ensure success, since innovation can be developed from a number of different models in order to meet in the best possible way the needs and culture of each company (Sundbo, 1997). All methodologies reviewed, however, follow the same rational for the innovation process, presented by a central model that contains four steps: search, select, implement, and learn (Tidd et al., 2008).

The first step, search, aims to seek and analyze internal and external environment of the organization, looking for threats and opportunities for change, for example, benchmarking between businesses and programs that encourages employees to propose new ideas. The second step is to select, which aims to understand that the ideas collected in previous step are feasible, taking into consideration technical aspects such as cost and time, and the organization's strategy. The third stage is intended to implementation of the selected ideas, turning them into projects, which usually follows concepts related to project management and engineering. The last step, named learning, derives from the process as a whole, for the particularities, and especially, the difficulties encountered on the way to bring something new to reality generate many lessons, which are learned and used in future innovation processes.

The model presented is endowed with certain generalism as it regards both products and services in its preparation. There is a representative model of the innovation process with the same rationale, but drawn from research exclusively with service companies. It is also divided into four steps: generate ideas (similar to the search phase of the previous model), transform the idea into an innovation project, development, and implementation - the latter two are similar steps to the implementation of the previous model (Sundbo, 1997).

The services model from Sundbo differs from the other in a crucial point, the learning step, which can be prejudicial if it contributes to perpetuating the erroneous idea that there is no systematic learning innovation in services. For that reason, it is considered important that both are presented in this paper.

These models help to consolidate the path pursued by organizations nowadays, which is performing innovation in a repetitive and systematic manner to make it a process that filters ideas and generates outputs like a pipeline to create new products and services, detached from randomness (Sebrae, 2009).

\section{Innovation Process Management}

There are several definitions of innovation management in the literature. Thus, from the innovation processonwards, each company uses the tools that best fit intotheir reality to manage it. In other words, there are no exclusive tools to manage innovation, as innovation should be rooted in the organization as a whole, across all different areasand in this sense, the tools used are multidisciplinary. 
Innovation management is well done when it integrates objective characteristics, such as goals and result measurements with subjective characteristics, such as creativity (Pacheco, Gomes, \& Silveira, 2013). Finally, innovative companies are those who routinely practice the management of innovation, in both aspects, separating it from a random event (Tidd et al., 2008). To better describe the concept of management of the innovation process in view of the present work, Figure 1 was prepared.

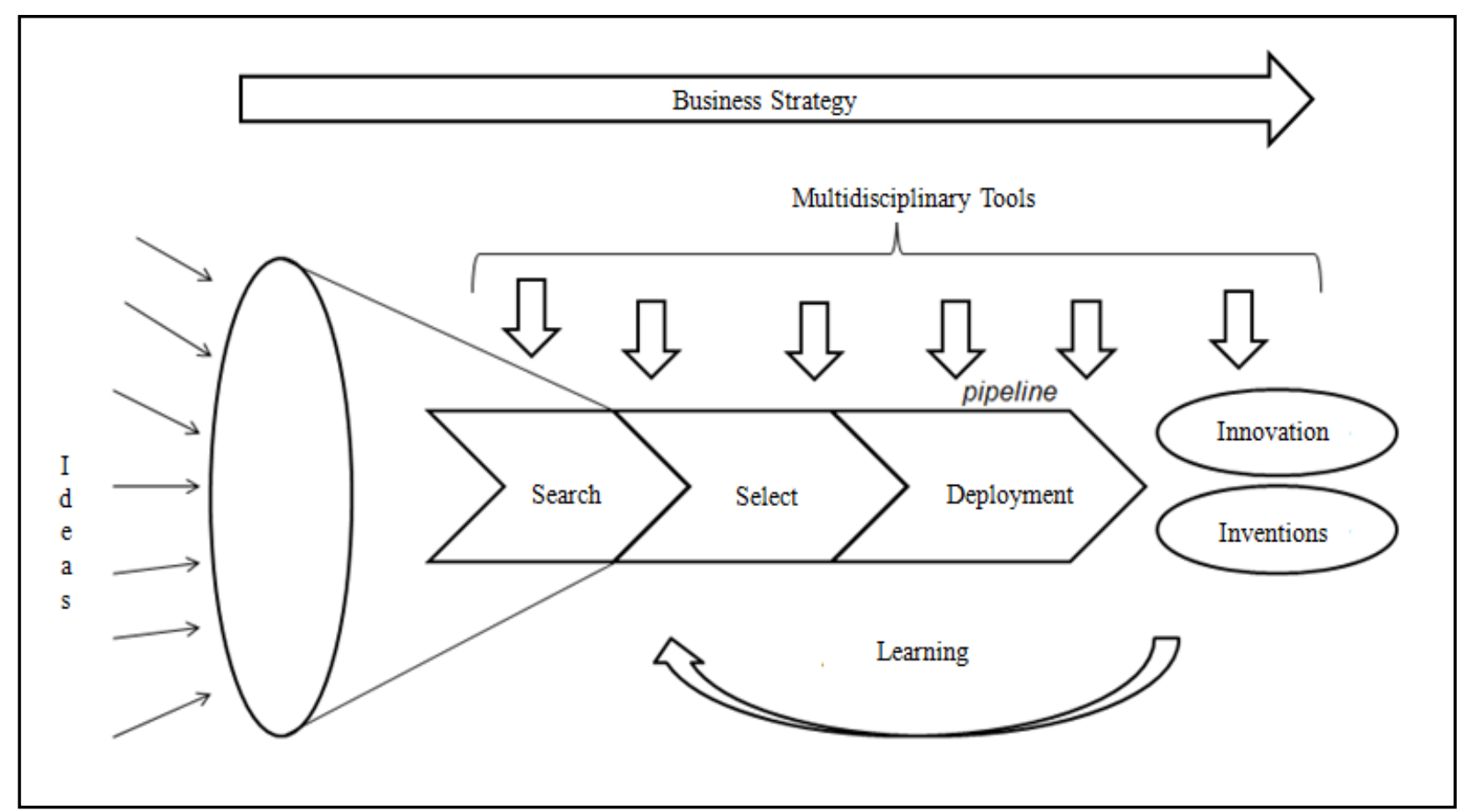

Figure 1. Innovation process management. Source: it was prepared by the author based on the concepts of Tidd et al.

(2008), Sundbo (1997), Sebrae (2009), and Pacheco et al. (2013).

The first item to be considered is the search phase, in which the organization operates like a large funnel, collecting ideas from diverse backgrounds. This is followed by the selection of ideas according to criteria predetermined, so that in the third stage, they can be implemented with prototypes and market testing (Tidd et al., 2008).

The outputs of this process are innovations and inventions in an uninterrupted pipeline (Sebrae, 2009), which are translated into new services offered, processes, markets, and routines in the service organization. If the process output generates results for the organization, then it is considered as an innovation, otherwise, it is only an invention. Both generate learning for future cases (Tidd et al., 2008).

Throughout the process of innovation, a variety of multidisciplinary tools assists in planning, control, and measurement of results, for example, the PDCA cycle and the matrix that assists in developing a consistent action plan, were called 5W2H among others (Pacheco et al., 2013). It is noteworthy that the vision and strategy of the company should direct the whole process and that, at all stages, especially in the first ones, the structure of the organization and its routines act as promoters of innovation to provide a creative and easy-to-interact environment (Sundbo, 1997).

This paper is highly important as it consolidates different aspects of innovation providing a holistic view on the topic. Also, it provides a service-oriented perspective, which relates to global current scenario. 


\section{Research Methods}

The research here presented is of qualitative nature, once it proposes a thorough investigation of reality, taking into account the scenario and experience of the interviewed agents as part of the responses obtained as reported by Bardin (1977). On the side, it is of exploratory nature, as it aims to provide familiarity with a certain problem and makes it more accessible and known. During the interviews, the researchers asked the same questions to all respondents, characterizing thus the process as a structured process. For the analysis of the results, within existing techniques of content analysis, the researchers decided to proceed with the categorical analysis, which proposes splitting the text into categories, found from similarities in different responses that are relevant to the response of the research problem as proposed by Bardin (1977).

\section{Profile of Respondents Enterprises and Respondents}

This research refers to micro and small businesses in the metropolitan region of Campinas, a large sized city (1 million inhabitants), located in the Federal state of São Paulo, which works with marketing of services in their portfolio. The profile of selected respondents was made up of 10 people with different job positions in five different companies, which were selected based on meeting determined proposed criteria, convenience, and the ease of access to the researchers.

The chosen tool for data collection was a structured interview in which the same eight questions were asked in the same order and manner for all respondents. The interviews took place during September and October, 2014 taking as average time, 40 minutes. The questions asked were adapted from the Brazilian National Quality Foundation (FNQ) materialas used to identify micro and small companies with excellence in innovation management and is part of their questionnaire constructed with the methodology of model of excellence in management (MEG). From the 13 questions proposed by FNQ in the questionnaire subsection "Innovation", we selected seven were selected and added onequestion following the response criteria and the objectives, as proposed by the research.

\section{Data Analysis}

Within the content analysis, it was decided to proceed with the categorical analysis. After literal transcription of audio interviews, NVivo version 10 was used for consolidation and data analysis. The test version of the software is available for downloading at the official software website.

The process of categorical analysis occurs following three key steps, as proposed by Bardin (1977): coding, categorization, and inference.

The encoding step took place with the perusal of all verbatim transcripts of interviews and, from that, full uploads into software named NVivo that supported the organization of content by question and relevance.

In the second step, categorization, it was necessary a new detailed reading of all answers obtained, but this time already organized by questions asked. From this, mooring was created with the help of NVivo tool, grouping similarities in the speeches of respondents in key points were also found in bibliography. The analysis was carried out afterwards, since the categories for grouping were defined only after reading and familiarization with the responses.

Finally, in the inference step, it was necessary to in-depth analyze information obtained in order to connect it to the theoretical aspects studied previously. In other words, it was necessary to analyze to identify key similarities and differences between reality and literature. The correlation matrix tool was used to help link the 
main theoretical aspects found in the literature with the specific objectives of the study and with the questions made to the respondents (and responses obtained from them). In the following section, it will present the analysis of data obtained, as well as excerpts from interviews conducted to serve as the argument proof of evidence.

\section{Result Analysis}

Two general approaches were identified, and from them, two relevant categories were selected in each, following the steps proposed by the categorical analysis (Bardin, 1977). Approaches and identified categories are described in Figure 2 below.

\begin{tabular}{|c|c|}
\hline Approach & Categories \\
\hline \multirow{2}{*}{$\begin{array}{l}\text { Subjective Features of } \\
\text { Innovation }\end{array}$} & Understanding of Innovation Concept \\
\hline & Innovative Ambience \\
\hline \multirow{2}{*}{$\begin{array}{l}\text { Objective Features of } \\
\text { Innovation }\end{array}$} & Innovation Process Management \\
\hline & Learning in Innovation Process \\
\hline
\end{tabular}

Figure 2. Definition of approaches and categories. Source: it was prepared bythe author from survey data.

\section{Approach 1: Subjective Features of Innovation}

Two main approaches were identified to help answer the research question, within the topic management of innovation process, as the integration of both is essential for success.

The first related to the subjective aspects of innovation (Pacheco et al., 2013) also studied with the nomenclature of informal interactions system (Sundbo, 1997) and strongly support structure with effective organizational routines to support the execution of innovation (Tidd et al., 2008). This approach is depicted in this study by two categories below.

Category 1: Understanding of innovation concept. It was observed that even without being familiar with the concepts espoused in the studied literature, respondents understand what innovation is. Most tend to perceive innovation as something that escapes the routine and that is linked to results for the company, as advocated by Tidd et al. (2008) and noted below:

Innovation I think that's when we can develop something that has not been thought out and has a utility. It's not just develop something new, but useless. Something that will help people's lives...will facilitate, a service or product with a certain utility. (Tidd et al., 2008)

It is worth highlighting that for the respondents of two companies, innovation is perceived only as something disruptive, which would necessarily provide a great leap of results for the company. Also, in these companies, innovation was identified with reactive context, that is, required only upon crisis. The excerpts below prove this argument: "So the crisis itself makes you innovate, pursue new things, new techniques... To be even more profitable"; "Innovation is a pioneer action in the segment share, which is what makes you pass in front of your competitors" (Tidd et al., 2008). 
This category proposed by the author and called "understanding of innovation concept" which can be justified by the positioning of Tidd et al. (2008) that innovation is the application of an invention that is converted into results for the company, whether incremental or radical. The Oslo Manual (OCDE, 1997) corroborates stating that, even if addressed to organizational changes, it is only considered as an innovation if there is measurable improvement in the results.

By the fragments presented and strengthened by the excerpt below, it emerges that respondents understand the concept of innovation, but they do not see it as a daily process, disconnected from randomness.

I'm always analyzing the sales area, asking them how the market is reacting... Yeah, and acting and from there, we... Exchanging ideas, decisions are made. (...) This is done informally, according to the progress of the work we talk and inform each other.

Category 2: Innovative ambience. This category indicates how the innovative ambience is managed within the companies studied, given their importance to the innovation process. Innovative ambience characterizes the subjective aspects that indirectly stimulate innovation as a constant practice in organizations.

In this sense, it identified, in the speech of respondents, three key elements which fall into this study window. The first is the favorable environment for the emergence of new ideas, followed by experimentation environment that tolerates error and the latter is the recognition of the employees involved in the innovation process. Each will work individually below.

Regarding the first, an environment enables the emergence of new ideas, it is noted that most of the answers obtained highlight the stimulating interaction and cooperation among employees on a daily basis, important elements for the construction of that environment, as advocated by Scherer and Carlomagno (2009) and Pacheco et al. (2013). The excerpts below demonstrate this observation:

I think the environment itself. Here everyone can put on their ideas and everyone has open doors here with us. We have a fully participatory management, they are involved in most matters of the company. (...) They participate and I think that's what we really want, this collaborative environment, because we also get a lot from their opinion.

Also, in two of the five companies studied, the favorable environment for the emergence of new ideas is not encouraged among company employees, as the activity of thinking new ideas is centered on the high leadership of the company. "Normally it is always from the management to the operational. Rarely, an idea from operational people gets to be discussed at the board, among the executive directors".

Regarding the second element identified in the speech of respondents - the experimentation environment with tolerance for error-it stood out in the responses again, the presence of the cooperation element is defended by Pacheco et al. (2013) as a factor that encourages this type environment.

Then you get the product and markets it and expect it to work, and it is not always so. Sometimes we launch a product or service... We do it all, plan, invest... I already invested 400, 500 thousand dollars on a product and it is kept in the drawer because it does not survive in the market. Even the people testing it and using it before, it might reach a point where it just stops, you never know why. (Pacheco et al., 2013)

One of the respondents pointed out understanding the importance of a tolerant environment to error, but showed that she finds it difficult to establish it due to lack of technical sources, as advocated by Tidd et al. (2008) as one of the basic elements for successful innovation. Technical sources are part of the support structure, as pointed out previously in this study, and provide tangible evidence to the execution of innovation, for example time, money, and adequate equipment. In this case, the issue indicated refers to the limited number 
of employees and departments in a small company, which impacts the time available for activities such as testing innovations.

So unfortunately there's no time to stop and talk and say "let's think about this". Because we don't have departments for this, what would be the correct (...) No, everything has to be from one source only, which slows the process.

Regarding the last identified element-recognition of employees involved in the innovation process-it was possible to clamp data from only four companies because one of them has only two employees. Out of these four companies, only two have adopted formal practices in this regard, as excerpt below.

If one had an idea and is working in this idea, and it works, he will become a partner of the company. There is no better recognition than that. In sales, the person who gave the idea will have the bonus attached to it. Sometimes there is cake too, parties and celebrations. There is always a celebration to recognize the person or team, but there is always some sort of bonus for them too.

As stated earlier, the other two companies do not adopt recognition practices and concentrate the whole conception of new ideas in the senior leadership of the company.

There is no financial recognition for leaders. I think the only recognition is that management and the board may allocate more confidence to the professional who is there, really engaged, wearing the company's shirt, seeking for a breakthrough. But regarding to financial bonus or any prizes, no, that does not happen.

In general, it was concluded that the studied companies expend energy and time in keeping a good focus on the subjective aspect of innovation, i.e., investing resources which support elements that stimulate primarily the generation of new ideas. This finding relates to the conclusions reached in the analysis of the first category, which stated that innovation is understood as concept, but not as a process. By not being seen as such, it is evident that the main focus of businesses is on prioritizing the rise of new ideas. However, as stated before, this is the step of innovation that is least possible to manage.

\section{Approach 2: Objectives Features of Innovation}

The second approach identified regards to the objective characteristics of innovation, and also studies under the nomenclature of strategic management system (Sundbo, 1997) and is complemented by Sebrae (2009) with the use of multidisciplinary tools in different steps of the process and the measurement of results obtained with this process (Pacheco et al., 2013).

Category 3: Innovation process management. Evidence of the tools used to manage each step of the innovation process was sought in this category. As stated in Section 2, the central model of innovation process consists of four steps: search, selection, implementation, and learning (Tidd et al., 2008). The service-oriented model also consisted of four steps: generate ideas, transform the idea into an innovation design, development, and implementation (Sundbo, 1997). The learning stage of the first model will be discussed in a different category due to its importance and to the fact that it is not a step considered in both models.

Regarding the first step, the search or generate new ideas can be converted into innovations, two companies presented in their routine a structured time to discuss ideas.

We decided to invest in these Fridays, which is precisely to take the people off the routine, the day to day, and leave them free for a period so they can talk, work on what they like and have ideas. It is fully open, everyone can talk and suggest. (...) I think it's a matter of practice, this process. Each time more they release themselves, loosen up and start giving ideas, suggesting. 
Companies perceive this aspect as much harder to manage (Sundbo, 1997). The recommendation to address this problem is to structure the process, detaching it from randomness (Hamel, 2007). A good example can be noted in the company mentioned above, that structured a formal time weekly to discuss and suggest new ideas.

As a complement, all companies studied described that they seek ideas from internal and external sources to the organization:

That's what I said, going to fairs, opening our minds. In fairs you see many new things, all that is new in market trends in design in the world happens in the fairs, so there you know everything that is happening. And the media shows that, in decorating magazines, for instance. So you have to be always catching up, always updated on the market to have new ideas.

Regarding the next stage of the innovation process - the selection of new ideas or transformation of the idea into an innovation project-most respondents indicated not having a formal procedure established with clear selection criteria, which differs than what is defended by Sundbo (1997) concerning the paradigm of strategic innovation as a driver for innovation. The companies studied stated that they work on the analysis of potential ideas, but periodicity of meetings varies by demand and criteria used are mostly subjective, not considering the organization as a whole.

(The selection of ideas) is studied case by case. Sometimes it is by trial and error, but is generally decided case by case.

In reality the ideas are discussed. An idea comes and is asked of the leaders that they review each and from there, ideas start to emerge, the pros and cons in the view of each. It is usually made a report with the opinion of all leaders and then it is re-evaluated individually. Each leader will see his or her points, their ideas, what is really doable, important. What is really relevant or not. Then the matter is discussed again until such time when it becomes a project.

The two companies in technology business developed their routine the concept of prototype or MVP (Minimum Valuable Product) to test their products and services on the market before releasing them. This relates to the "implementation" stage in the first model and "development stage" in the second.

Then you begin to schedule in-person meetings to show the prototype to see the interest of the person, to see if they really want it, if they would like to have the product and especially if they would pay for the product. [...] Of course, we've learned already that it does not help to make the investment to find out later that it was not quite what the market wanted. So this is a process that is clear to everyone here. First let's test and see if there is interest, to see whether it is worth continuing the investment.

Besides that, other companies follow the deployment of innovations without formal measurement tools or monitoring. This is done only by the feeling generated by the released innovation, years of marketing experience, and conversations with employees working with innovation.

Monitoring is still centralized in the executive management. So how the project will always be divided between areas, as I already explained, each leader will monitor the performance of their staff in implementing that innovation in the way he feels is appropriate.

Regarding the measurement of the benefits of innovation, Tidd et al. (2008) and other authors quoted throughout this study, and argued the necessity to exist direct or indirect financial results for the company accomplished through the novelty for it to become an innovation. In this regard, it was noted that most companies studied only measure the impacts of innovations in a reactive perspective, that is, only when there is 
a necessity. None of the companies routinely calculates what percentage of total sales comes from innovations, for example.

We try to analyze the result, not necessarily financial, it could be increase of contacts, more sales, margin increase. Each innovation has its pro. The last times that results were analyzed, it happened by necessity, but we are now trying to structure and improve it, but haven't started yet. There are tools that an IT company is developing and can be used to measure those results to us.

Only one of the companies studied measures the benefits of innovation formally and acts upon it.

This measurement is made through the financial area. They go get the financial net result of this investment and also the customer satisfaction survey. The staff of marketing area, which is a contractor, do the survey after each implementation, there is a systematic for it. Usually, these results are passed along at a meeting in a more informal manner.

Thus, it can be concluded that service companies find it difficult to structure and formalize the steps of the innovation process so that it is connected to their daily lives, as proposed by Hamel (2007). There are specific practices aimed at some specific stages of the process and it is clear that companies that work with technology are a bit more advanced in this respect, but in general, there is a gap between literature and reality at this point.

Management practices are few, isolated, and instinctive. This conclusion is also related to the observed fact that the companies studied do not see innovation as a process, which blurs to them the real need to use tools to manage it.

Category 4: Learning in innovation process. This category reflects how learning occurs in micro and small companies studied, from the point of view of the innovation process. Therefore, the analysis considers two main elements identified in the speech of respondents: the first is the detention of knowledge, including information-sharing, interactions across the enterprise and the active involvement of people internally during innovation process; and the second is the management of lessons learned during the different attempts to innovate (Scherer \& Carlomagno, 2009; Tidd et al., 2008). The first connects to the arrest of knowledge, defended by Scherer and Carlomagno (2009) as part of an organizational structure that can inhibit innovation if knowledge in centralized and information not shared. Tidd et al. (2008) confirmed the importance of engaging the entire organization in the innovation process because the support structure plays a critical role in the success of the process.

In this sense, within the studied companies, it was found that most of them have information-sharing practices with the team, even if informal. The excerpts below prove this conclusion.

The advantage of being a small business is that communication is very easy here, man. Even verbal, you know, we can exchange one idea with the staff here and even the partners are very close to us. So you can, for example, present an idea in reserved periods.

Two of the companies interviewed keep the knowledge only at the top of the organizational chart, which impacts the involvement of the organization as a whole and the timing available for innovation.

Leaders don't receive a report with printed results, not financial nor operational. We are only told that the new program worked out and eventually if it got some notation or improvement pointing in that project, and when is possible, we do the improvements suggested if it is still in the budget projected for deployment.

In order for learning to happen, innovation needs to be treated as a process and the focus of successful management of innovation, both for products and for services, should be learning (Sebrae, 2009). It was 
observed some similarity in the way the companies studied (and that share information, as it is a prerequisite for this second analysis) address this topic and what was described by Sundbo (1997) in the literature. The innovation process in services is still based on trial and error. There are attempts to learn, but informally, with the experience of time, for instance, and not how it should be done, that is, systematically and efficiently (Sundbo, 1997).

I spoke to you that we have the know-how of development because we have been through several processes and several launches, so we know what works and what does not. (...) Like any cultural process, it is informal. Learning happens naturally within the group.

\section{Conclusions}

A detailed analysis of the categories identified in the speech of respondents of this study and presented above highlights the four main elements discovered: (i) the studied companies understand the overall concept of innovation, but do not visualize it as a process; (ii) there are isolated management practices to the theme, but they are instinctively realized and not in a structured manner; (iii) companies are concerned mostly to promote practices that encourage innovative ambience, mainly related to the generation of ideas; and (iv) learning occurs informally and unstructured over time, there are no practices or tools that encourage management of the knowledge obtained from the innovation process.

On the first consideration (i), it is understood by the transcribed excerpts that the companies surveyed know what an innovation is, but regarding the efforts to guarantee it consistently, it is noticeable that there is no systematic and continuity assured.

On the second consideration (ii), it is clear that companies whose field of activity is somewhat connected to technology may manage some steps of the innovation process in a more structured way. When considering all the companies approached, however, it stands out that practices linked to the management of different aspects of innovation (mainly the objective ones) happen instinctively, according to the personal perception of those who responsible for it, accompanied or not by the opinions of employees.

Regarding the third statement (iii), it is evident that service-oriented businesses realize the importance of an effective support structure for successful innovations and thus, demonstrate the effort to maintain a work environment conducive to such. Furthermore, it was noted that there is preponderance on the approach taken by companies to the subjective aspects of innovation, mainly related to the generation of ideas - even if there might not be any systematic effort to bring these ideas to life.

Regarding the last element (iv), it can be assumed from the transcripts that companies are interested in keeping the knowledge obtained with innovation, however, the understanding of respondents is that this can only be done instinctively and naturally. This means that, in their point of view, it is not possible to structure the learning into a process. Innovation often happens in a trial and error approach, what differs from the literature, which clearly states that learning is a key element for a successful process of innovation and can be stimulated in the day-to-day (Sebrae, 2009).

In this sense, and in response to the first specific goal of this paper - exploring how managers and employees of micro and small service-oriented companies understand, how and through which methodologies manage the innovation process - it was shown that there are still difficulties in managing mainly the objective aspect of innovation, for example, establishing goals, tools, clear criteria for selection of ideas, deployment of innovations, and measurement of its results, which could indicate a relation to the fact unveiled that micro and small 
service-oriented businesses understand the concept of innovation, but do not perceive it as literature describes - an ongoing process detached from randomness (Hamel, 2007). Topics such as lessons learned during the process and measurement of the results of an innovation are deficient in service-oriented companies as a whole.

As for the second specific goal—understanding how managers and employees perceive and manage innovative ambience in these types of companies - it was noted an effort to establish an environment that encourages the rise of new ideas, such as facilitation of interaction, experimentation, and recognition. This is translated as the subjective aspect of innovation, also called support structure, defended by Tidd et al. (2008) as a key factor in the successful management of the innovation process. In this aspect, there was similarity to the literature in most cases, except one, which highlights the lack of technical sources. In this way, problem question and the goals of this study were answered.

\section{Contributions and Limitations of the Research}

Considering the presented conclusions and answers obtained for the proposed objectives, one can assume that this paper has contributed to the expansion of the academic content about the theme "Management of the innovation process in service-oriented companies", which is still little explored, especially in Brazil.

In practical terms, the contribution of this study is that it presents company managers and employees with the opportunity to learn more about innovation and compares their reality with literature and also to other similar companies. It has a holistic and data-based approach on innovation. Also, the results presented in this paper could serve as a trigger to awaken the need of a cultural change in managers and employees, hopefully, leading to the adoption of initiatives that foster a culture of managing the innovation process - as a routine and as a strategy to leverage results.

However, one can point out limitations to this research. First one relates to the diversity profile of the chosen respondents. Since they are from different acting branches, connected only by the element of having services in their portfolio, results of the analysis can be considered generic and not applicable as a general rule; the second limitation refers to the number of respondents, which was limited to 10 . Due to the low number of people interviewed, inferences cannot be made to the Campinas metropolitan region as a whole from the obtained results. In a future analysis, it could be interesting to repeat the interviews with a larger sample.

\section{References}

Afuah, A. (2003). Innovation management: Strategies, implementation and profits. New York: Oxford University Press.

Bardin, L. (1977). Análise de conteúdo. Lisboa: Edições 70.

Cassiolato, J. E., \& Lastres, H. M. M. (1998). Inovação, Globalização e as Novas Políticas de Desenvolvimento Industrial e Tecnológico. Rio de Janeiro.

Gorni, P., Dreher, M. E., \& Machado, D. (2009). Inovação em Serviços Turísticos: a percepção desse processo em agências de viagem. Observatório de Inovação em Turismo-Revista Acadêmica, IV(1). Março.

Hamel, G. (2007). The future of management. Boston: Harvard Business School Pub.

OCDE (Organização para Cooperação Econômica e Desenvolvimento). (1997). Manual de Oslo: proposta de diretrizes para coleta e interpretação de dados sobre inovação tecnológica. Paris: OCDE, p. 136 (Traduzido em 2004 sob a responsabilidade da FINEP - Financiadora de Estudos e Projetos - das edições originais em inglês e francês).

Pacheco, L. M., Gomes, E., \& Silveira, M. A. (2013). Metodologias de gestão da inovação em uma perspectiva comparada: Contribuição para aplicação em pequenas e médias empresas. In: ALTEC 2013-XV Congresso Latino-Iberoamericano de Gestão de Tecnologia, 2013, Porto. Anais do ALTEC-2013.

Scherer, F. O., \& Carlomagno, M. S. (2009). Gestão da inovação na prática: como ampliar conceitos e ferramentas para alavancar a inovação. São Paulo: Atlas, 9. p. 150. 
Sebrae (Serviço Nacional de Apoio à Pequena e Micro EMpresa). (2009). Gestão da Inovação: inovar para competir. Guia do Educador. Brasília: Sebrae.

Sundbo, J. (1997). Management of innovation in services. The Service Industries Journal, 17(3), London: Frank Cass. Sundbo, J., \& Gallouj, F. (1998). Innovation in services. SI4S Synthesis Paper, 2.

Tidd, J., Bessant, J., \& Pavitt, K. (2008). Gestão da Inovação. Porto Alegre: Bookman. 